worldwide public health research and intervention instead of merely serving as an information clearinghouse. priority for the WHO since its inception 50 years ago, Brundtland said uneven implementation has hindered progress. "We can not eradicate malaria.
Although malaria has been a

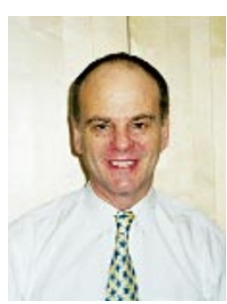

David Nabarro the distribution of insecticidecoated bednets, which have cut malaria rates by as much as 25 percent in African trials. Other tasks include helping affected countries to internalize malaria control and tracking outbreaks for more efficient resource deployment.

According to newly appointWe do not have the tools," she said, "But we can roll back morbidity and mortality." Between 300 and 500 million cases of malaria are reported worldwide each year, and the parasite kills more people than any other infectious disease except tuberculosis.

The WHO has set aside \$19 million for RBM up to the end of 1999 , at which time an additional $\$ 6.5$ million will be donated from various governments and UN agencies such as UNICEF and the World Bank.

Much of RBM focuses on community health and education efforts, including merly director of Health and Population at the UK Department for International Development, the campaign aims to unite a host of sometimes discordant anti-malaria efforts.

Nabarro will oversee the New Medicines for Malaria Venture, a pharmaceutical/ WHO collaboration that aims to develop new drugs for the disease (Nature 395, 417; 1998); the Multilateral Initiative on Malaria (MIM), a research collaboration that includes the NIH, UK Medical Research Council and the Pasteur Institute ed RBM manager David Nabarro, for- in France; and the Africa Initiative, a resource network to channel information and supplies to countries where they are needed. The groups will meet in Durban, South Africa on March 15-19th 1999, at the MIM African Malaria Conference, to discuss the range of malaria research and prevention efforts under the RBM program.

Nabarro describes himself as the "conductor of the orchestra," he explains, "there are lots of things going on in malaria but they won't be effective unless they all play together. I set the strategy and get everybody assigned to it." He believes it will take two years to ensure that the system operates smoothly. "My personal goal is halving the amount of death due to malaria by 2010," says Nabarro, adding "I've given up a very comfortable job to do this because I think, in my discipline, it's the most important thing around."

BRIAN VASTAG, BETHESDA

\section{New infectious disease research funding}

The London-based Wellcome Trust and the Burroughs Wellcome Fund in the US have announced a new \$25 million grant program for infectious disease research which includes two unusual stipulations: Firstly, the emphasis of the initiative is not on HIV or malaria-which the two charities believe to be well supported by other organizations-but on diseases such as diphtheria, dengue and typhoid fever. Secondly, teams applying for funding must include at least one scientist from the US or Canada, one from the UK, and one from a developing country.

Public health experts have long advocated assistance for developing countries' scientists to increase the number of experts 'on the ground' where diseases are most likely to emerge, but traditional competitive grants tend to favor scientists in industrialized countries. Thus, the initiative aims to foster greater international collaboration among researchers and bolster the scientific infrastructure of developing countries.

Victoria McGovern, Program Officer for the Burroughs Wellcome Fund, hopes the program will inspire scientists to study a wider range of public health problems. "The ones that come to mind immediately are really the diarrheal diseases because they have a huge disease burden," says McGovern. Projects may range from designing new control strategies to initiating basic studies of the future. pathogen biology, but the emphasis will be on work with direct applications, she explained.

The five-year grants, which will range from \$2-4 million, may ultimately inspire the creation of more multina- tional research teams. But because of the tight deadline for the first round of applications, which are due by January 15 th, officials at the two charities concede that the initial grants will probably boost existing collaborations rather than generating new ones.

\section{Alan Dove, New York}

\section{Spain introduces repatriation grants}

In an effort to encourage Spanish biomedical researchers working abroad to return home, the Fondo de Investigaciones Sanitarias (FIS), a department of the Ministry of Health, last month announced a grant program to enable M.D./Ph.D. researchers who have worked abroad for a minimum of six years to return to Spanish laboratories. According to Jaume Bosch, from the Interministerial Commission of Science and Technology, young scientists are the target of the program with the long-term goal of boosting Spain's research base and creating a platform to which more senior Spanish investigators will be attracted in

Basic biomedical research in Spain is done largely in Universities and research centers run by the government-funded Higher Council for Scientific Research (CSIC). However, the new FIS-sponsored grants will support research within hospital departments, and it is hoped, therefore, that they will enhance the link between basic and clinical research as no other program does currently.

The FIS, which is the second largest funder of public biomedical research in Spain after the CSIC, will invest US\$1.35 million in the program for 1999. FIS is already slated to receive a budgetary increase of 12.5 percent to US\$37.5 million next year, which will allow the returning scientist program to be doubled in 2000. Optimists at the FIS predict that the program will repatriate as many as 300 investigators within the next six years.

The biggest problem that the initiative will have to overcome are the poor prospects for long-term, senior research careers in Spain. FIS returning researchers will be supported for up to three years in the first instance, with the possibility of an additional three years backing. However, a similar project by the CSIC offering five year contracts has already failed on account of the lack of opportunities for scientists after this period-at the end of their CSIC research contracts, many simply returned abroad.

$$
\text { XAVIER BOSCH, BARCELONA }
$$

